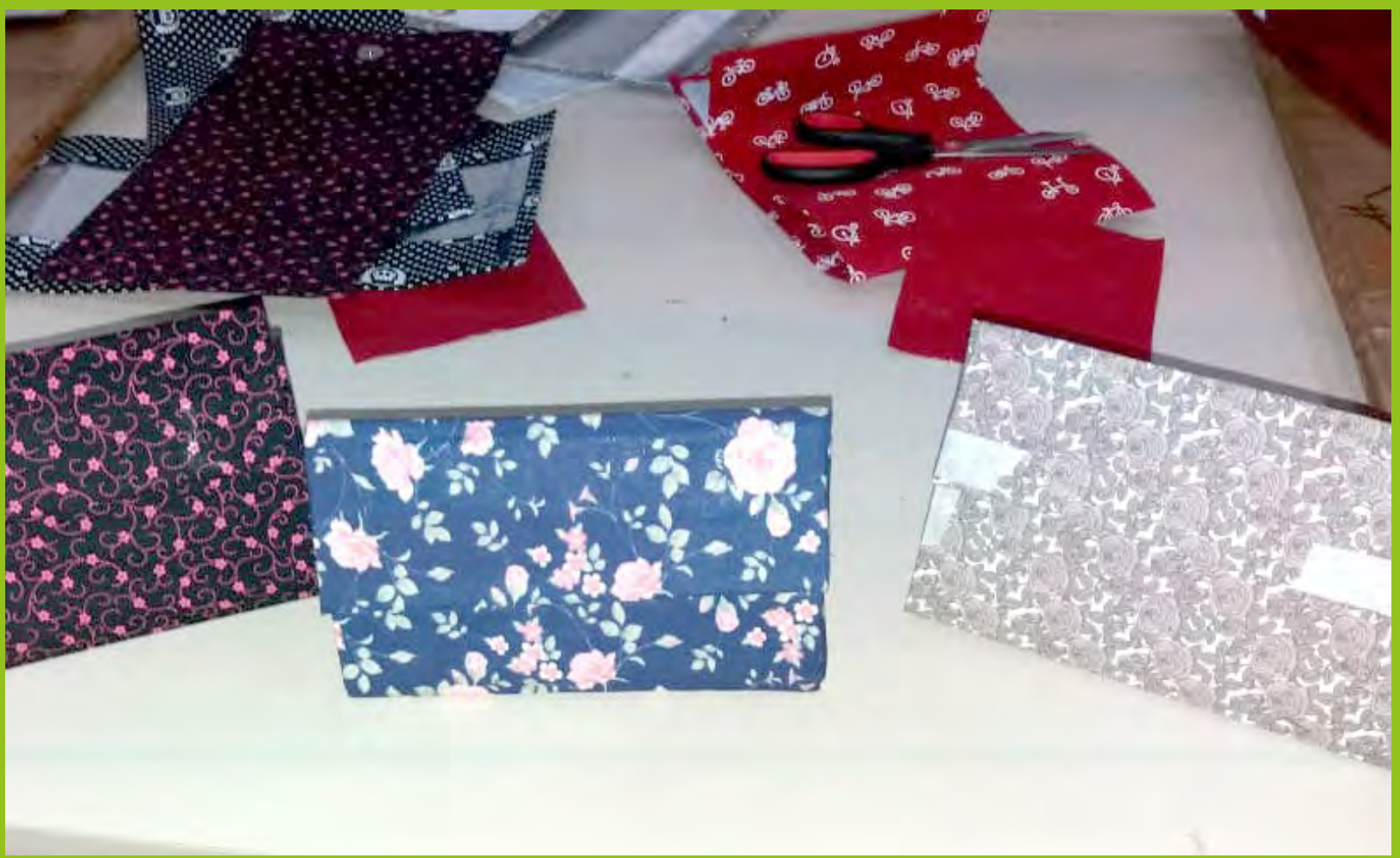

\title{
Empreender na escola - aplicando o Miniempresa
}

Rogério Ruas Machado ${ }^{1}$ rogerruas@unifesspa.edu.br

Gustavo Passos Fortes ${ }^{2}$ gustavo.fortes@unifesspa.edu.br

Maysa Tharsilla da Silva Lima ${ }^{3}$ maysa.tharsilla@unifesspa.br

Juliana Moreira dos Santos ${ }^{4}$ julianamoreira@unifesspa.edu.br

1 Doutor em Administração e Professor do Magistério Superior na Universidade Federal do Sul e Sudeste do Pará.

2 Mestre em Administração, Doutorando em Administração na Universidade Federal de Goiás e Professor do Magistério Superior na Universidade Federal do Sul e Sudeste do Pará.

3 Discente do curso de Administração da Universidade Federal do Sul e Sudeste do Pará.

4 Graduada em Administração, Especialista em Gestão Pública e Tributária na Universidade Federal do Sul e Sudeste do Pará e Mestranda em Administração na Universidade Federal de Sergipe. 
Com a intenção de oferecer experiências práticas em negócios por meio da organização e da operação de uma empresa, foi proposto o projeto Miniempresa, por professores da faculdade de Administração da Unifesspa e com parceria, no suporte metodológico, da ONG Junior Achievement. 0 projeto foi desenvolvido com alunos do terceiro ano do ensino médio de uma escola pública do interior do Estado do Pará. Os alunos aprenderam conceitos de empresa, livre iniciativa, mercado, comercialização e produção e constituíram uma miniempresa de ecobags. Por meio desta, aprenderam a planejar, produzir e vender um produto, dentre outras atividades. Constatou-se que o projeto contribuiu para a formação dos adolescentes quanto a conhecimentos e perspectivas para o mercado de trabalho e quanto a aspectos comportamentais e de interação grupal.

Palavras-chave: Empreendedorismo. Educação empreendedora. Miniempresa.

\section{ABSTRACT}

With the intention of offering practical experiences in business through the organization and operation of a company, the project Miniempresa was proposed by professors of the Business School of Unifesspa in partnership with the NGO Junior Achievement, in the methodological support. The project was developed with senior students from a public high school in the interior of the State of Pará. The students learned concepts of company, free enterprise, market, commercialization and production, and constituted a minicompany of ecobags. This way, they learned to plan, produce and sell a product, among other activities. It was found that the project contributed to the training of teenagers in terms of knowledge and perspectives for the job market and in terms of behavioral and group interaction aspects.

Keywords: Entrepreneurship. Entrepreneurial education. Mini business.

\section{Introdução}

Quando os jovens começam a se preparar para a entrada no mercado de trabalho, costumam considerar algumas opções. As mais comuns são: arrumar emprego em uma grande empresa, prestar um concurso público e, mais recentemente, montar o próprio negócio. Cientes deste cenário e da carência, nas escolas, de práticas de ensino voltadas para conhecimentos e ações de empreendedorismo, um grupo de professores e acadêmicos do curso de Administração da Unifesspa propôs um projeto de extensão com o objetivo de proporcionar a estudantes de nível médio experiência prática em economia e negócios por meio da organização e operação de uma miniempresa.

A proposta foi consolidada em uma escola pública do interior do Pará, junto a estudantes do terceiro ano de ensino médio (inicialmente 30 estudantes). Foram desenvolvidos quinze encontros (jornadas) ao longo do ano de 2019, nos quais a equipe do projeto, composta por 04 professores e 08 acadêmicos do curso de ADM, sendo uma bolsista, conduziu práticas sob referencial e suporte metodológico de um dos programas da ONG Junior Achivement, especialmente desenvolvido para a faixa etária do público envolvido.

A equipe desse projeto foi exposta aos problemas que porventura ocorrem nas organizações (miniempresas), desde o estudo do cenário no qual elas estão inseridas até os processos operacionais provenientes das ações necessárias para produzir bens ou serviços. As equipes, que foram constituídas por estudantes da escola de ensino médio, trabalharam o conceito de empresa e suas origens, com ênfase nos tipos de empresa, e nos valores sociais da livre iniciativa, apontando-se que, a partir de uma necessidade, são produzidos bens com vistas a gerar satisfação.

Os alunos foram expostos a situações nas quais necessitaram de exercitar suas capacidades de criar novos produtos ou serviços (por meio do brainstorming) que necessariamente envolvessem determinação de custos operacionais, ponto de equilíbrio e preço de venda, por exemplo.

Os graduandos, orientados pelos docentes da universidade, mostraram aos alunos da escola (ensino médio) como funcionam as quatro principais áreas de uma empresa: marketing, finanças, recursos humanos e produção. Essas ações possibilitaram aos membros da equipe (graduandos) implantar o espírito empreendedor nesses jovens.

Nesse sentido o objetivo desse projeto foi proporcionar aos alunos da escola experiência prática em economia e negócios por meio da organização e operação de uma empresa (miniempresa).

\subsection{Entendendo o empreendedorismo e a educação empreendedora}

0 empreendedorismo desponta com destaque nas políticas econômicas dos países desenvolvidos e em desenvolvimento, e o empreendedor é entendido como aquele possuidor de capacidade diferenciada 
e inovadora (BAGGIO; BAGGIO 2015, DRUZIAN et al., 2017). Para Dornelas (2008) e Dolabela (2006) o empreendedor é entendido como sagaz e atento aos riscos, antecipando os acontecimentos futuros com intenção de tomar decisões acertadas, explorando as oportunidades. Além dessas características o empreendedor é um ser apaixonado, dedicado e otimista, sem esquecer que é imprescindível o produto ou serviço apresentar valor para a sociedade.

ParaDrucker(2017), o empreendedor despertao papel transformador na sociedade, àmedidaqueinsere inovação e valor agregado à comunidade. Sendo assim, inteirar o público jovem acerca do empreendedorismo pode ser um caminho para disseminar o conceito e a importância de se empreender. Importante inserir essa ideia em escolas, cursos profissionalizantes e de graduação para possibilitar o entendimento e impulsionar a prática do empreendedorismo por meio da educação empreendedora (DRUZIAN et al., 2017).

Por meio da educação pode ser visto o desenvolvimento de sujeitos críticos, inovadores e proativos, especialmente para enfrentar o mercado competitivo em constante mudança na sociedade. Oportuno realçar a necessidade de empreender para fins de transformação social, sustentação econômica e o desenvolvimento regional. Educadores necessitam de estar atentos para a educação voltada para o empreendedorismo, em contraponto aos modelos lineares em que estão embasadas as abordagens mais conservadoras na educação (NECK; GREENE, 2011; DRUZIAN et al., 2017).

Druzian et al. (2017) entendem que, além de ser necessário criar novas oportunidades para as pessoas competirem no mercado, há necessidade de execução de novos produtos ou serviços em ambientes inesperados sob a perspectiva do empreendedorismo.

0 pensamento de que o empreendedorismo é uma característica inata ao indivíduo deve ser afastado, como preconizam Silva e Pena (2017), especialmente pelo fato de que as habilidades empreendedoras podem ser repassadas, ensinadas e absorvidas por outros indivíduos (DORNELAS, 2008; YUSOFF et. al, 2015; SILVA; PENA, 2017). Para Bizzoto e Dalfovo (2001), uma consequência da visão inatista para a sociedade brasileira é a crença, por parte da maioria das pessoas, de que não nasceram com dom para empreender e, por isso, não conseguiriam alcançar sucesso com suas empresas.

Os behavioristas discordam e atestam que qualquer pessoa é capaz de aprender a empreender, por mais que não apresentem aptidão em qualquer área do conhecimento relacionada a empreendimento. No entanto, é necessário que o aprendizado apareça fomentando a construção do conhecimento pelos alunos, com interações com o professor (BIZZOTTO; DALFOVO, 2001).

Ensinar empreendedorismo como um processo linear é incoerente, visto o caráter imprevisível que ele apresenta. 0 ensino do empreendedorismo necessita de uma abordagem mais abrangente, contemplando metodologias ativas baseadas em experiências e ações (SARASVATHY; VENKATARAMAN, 2011; NECK; GREENE, 2011; SILVA; MANCEBO; MARIANO, 2017). Para Vieira et al. (2013), a educação empreendedora emergiu apontando a possibilidade de ser ensinada e aprendida.

Henry, Hill e Leith (2005) lembram que o empreendedorismo foi visto como subárea da Administração, e que há necessidade de programa de avaliação por parte dos envolvidos com a educação empreendedora para que se possa entender os resultados alcançados. É comum um contexto onde os sistemas educacionais, na área de Administração, sejam criados e programados para capacitar os indivíduos a ocuparem cargos em grandes corporações. No entanto, para ser empreendedor necessita-se de construção e desenvolvimento de características onde o aluno assuma o centro do processo de aprendizagem (SCHAEFER; MINELLO, 2016).

0 desdobramento dessa cultura educacional é adequado para que as pessoas se tornem empregadas, e isso se constituiu em um costume de difícil desconstrução. Portanto, estimular o empreendedorismo é um processo que ainda apresenta resistência. (MALACARNE; BRUSTEIN; BRITO, 2014).

As instituições de ensino vêm promovendo o empreendedorismo de forma isolada e apenas preconizam a administração de negócios e a tecnologia (LORENTZ, 2015). Para Mendes (2011), Tschá e Cruz Neto (2014) o empreendedorismo deve contemplar um conjunto de ações a partir das quais os discentes devem ser orientados a ampliar as próprias ideias. A sugestão de Schaefer e Minello (2016) é a de que o ensino possa ocorrer de forma integrada, interdisciplinar, harmonizada e transversal, tendo assim mais sucesso na formação empreendedora.

Para Silva, Mancebo e Mariano (2017), o sujeito (futuro empreendedor) deve ser entendido como sujeito da ação, e a educação empreendedora deve ser tratada como um método para que se alcance relevante espaço no contexto acadêmico, social e econômico. Essa perspectiva é congruente com Lopes (2010), que defende, na educação empreendedora, modelos experienciais, práticos e coerentes com o mundo real, que agucem no aluno a imaginação e a posterior análise, visualização de oportunidades e a consequente solução de problemas. Para esse alcance, é fundamental o papel do professor como facilitador e dinamizador, aquele que fomenta o aprendizado no sentido de, como afirmam Dolabela e Fillion (2013), ensinar a pensar como empreendedor.

"Ensinar" o empreendedorismo requer uso, aplicação e atuação metodológica interativa entre os envolvidos, como método de ensino-aprendizagem. Essa atividade depende de diferentes tipos de pessoas 
e elas devem fazer um alinhamento entre teoria e prática para fomentar o espírito e a atitude empreendedora. (NECK; GREENE, 2011; SARASVATHY; VENKATARAMAN, 2011; SILVA; MANCEBO; MARIANO, 2017).

Seria interessante, pensando no protagonismo do aluno, ressaltar o parágrafo 70 do Art. 35 da Lei de Diretrizes e Bases da Educação Nacional- Lei 9394/96, incluído pela Lei no 13.415 de 2017 (BRASIL, 2017), que versa: "Os currículos do ensino médio deverão considerar a formação integral do aluno, de maneira a adotar um trabalho voltado para a construção de seu projeto de vida e para sua formação nos aspectos físicos, cognitivos e sócio emocionais."

\section{Aspectos metodológicos}

Voltado para estudantes do ensino médio do segundo ou terceiro ano dos turnos matutino e vespertino, o projeto foi desenvolvido em encontros (em jornadas semanais) realizados na escola no período noturno. Os estudantes aprenderam conceitos de livre iniciativa, mercado, comercialização e produção, acompanhados pela equipe do projeto. Buscou-se atender ao objetivo de proporcionar aos estudantes experiência prática em economia e negócios por meio da organização e operação de uma empresa (miniempresa).

A presente pesquisa caracterizou-se como qualitativa e descritiva ao buscar retratar e descrever as características do projeto aplicado, considerando a profundidade dos dados, a subjetividade do pesquisador e a exploração dos fatores envolvidos (NEUMAN, 1997). Com a finalidade de entender o comportamento dos alunos envolvidos no projeto, esse tipo de pesquisa foi o escolhido.

Foram utilizadas técnicas de revisão de literatura, a observação sistemática in loco e entrevistas. Para Gil (1994) a observação sistemática é comumente utilizada quando há necessidade de descrever de forma precisa os fenômenos, e o pesquisador sabe quais aspectos do grupo são relevantes para alcançar o objetivo pretendido. A entrevista, por sua vez, é uma metodologia utilizada para coletar dados que considera pontos de vista sobre os fatos além daqueles que podem ser observados pelo pesquisador (GASKEL, 2014).

No decorrer dos encontros, os membros da equipe abordaram temas das áreas de Marketing, Finanças, Recursos Humanos e Produção, com vistas à introdução da proposta de organização de uma miniempresa. 0 projeto Miniempresa, proposto pela equipe, é parte do primeiro programa criado pela Junior Achievement (JA) Internacional, em 1919, quando dois empresários americanos perceberam que faltava nas escolas um impulso ao espírito empreendedor dos jovens. Começou a ser realizado no Brasil em 1983, passou por um período de pausa e em 1994 voltou com força total (JUNIOR ACHIEVMENT BRASIL, 2021)

Com relação à seleção dos alunos do ensino médio que participaram, foi feita uma apresentação para todas as turmas da escola acerca do projeto, sempre articulada com a direção geral. Em seguida foi passada uma lista para manifestação de interesse por parte dos alunos (99 alunos manifestaram interesse) e logo após foi solicitado aos professores da escola que auxiliassem com a seleção, levando em consideração critérios como desempenho em sala de aula e potencial para tomar iniciativa. Terminado esse processo, foi possível iniciar o projeto com 30 alunos.

As funções responsáveis por cada área do empreendimento estão contempladas em material disponibilizado pelo método da JA e foram bem explicadas aos alunos. A partir desse referencial os discentes foram divididos em grupos: o responsável pelo marketing estabeleceria metas de vendas; o da produção informaria quantas unidades seriam fabricadas; o financeiro reportaria sobre a receita até a presente data; $e$ o de recursos humanos comentaria sobre a motivação da equipe, dentre outras atividades.

A decisão sobre o que (objeto) iria ser produzido foi tomada por meio de assembleia, discussão, apresentação e votação. Importante mencionar que a participação e contribuições ocorreram prioritariamente por parte dos alunos, e eles chegaram à conclusão de que ecobags (bolsas ecológicas) seria o produto a ser trabalhado. Em seguida o valor do produto foi calculado, levando em consideração os custos e o preço de mercado de produto similar.

0 recurso para a produção do item escolhido foi conseguido por meio das vendas de ações da miniempresa, entregues a cada acionista (achiever) em troca de um valor estipulado. Com as vendas das ecobags, os valores retornaram. Esse processo também aparece explicitado em detalhes no material disponibilizado pela JA (JUNIOR ACHIEVEMENT BRASIL, 2014).

\subsection{Descrição das atividades}

Em novembro de 2018 o coordenador do projeto entrou em contato com a direção da escola de ensino médio e firmou um contrato com termo de compromisso. Em dezembro de 2018 houve um acordo entre o coordenador do projeto e o responsável pela Comunicação e Projetos da ONG Junior Achievement, a fim de firmar um contrato de adesão (parceria). 
0 quadro 1 ilustra as fases, a descrição e o período das ações do projeto:

Quadro 1 - Fases do projeto

\begin{tabular}{|c|c|c|}
\hline FASES & DESCRIÇÃOO & PERIODO \\
\hline Oficialização & $\begin{array}{l}\text { Projeto aceito dentro da Pró-Reitoria de Extensão e preparação da } \\
\text { aluna bolsista. }\end{array}$ & $\begin{array}{l}\text { Janeiro a março de } \\
2019\end{array}$ \\
\hline $\begin{array}{l}\text { Organização do } \\
\text { cronograma }\end{array}$ & $\begin{array}{l}\text { Reuniões com a bolsista para delinear as fases, juntamente com a } \\
\text { coordenação da escola que seria atendida. }\end{array}$ & $\begin{array}{l}\text { Março e abril de } \\
2019\end{array}$ \\
\hline $\begin{array}{l}\text { Apresentação do } \\
\text { projeto }\end{array}$ & $\begin{array}{l}\text { Apresentação do projeto todos os alunos da escola para que } \\
\text { pudesse ser feito um processo seletivo. }\end{array}$ & Abril de 2019 \\
\hline $\begin{array}{l}\text { Preparação / } \\
\text { Distribuição do material } \\
\text { para os voluntários }\end{array}$ & $\begin{array}{l}\text { Entrega do material disponibilizado pela JA ao grupo de } \\
\text { acadêmicos voluntários da universidade e discussão acerca do } \\
\text { conteúdo. }\end{array}$ & Maio de 2019 \\
\hline Início do projeto & $\begin{array}{l}\text { Confirmação da participação dos alunos de ensino médio } \\
\text { selecionados e início do projeto. }\end{array}$ & Maio de 2019 \\
\hline $\begin{array}{l}\text { Reuniões de } \\
\text { acompanhamento }\end{array}$ & $\begin{array}{l}\text { Reuniões semanais de acompanhamento para discutir a evolução } \\
\text { do projeto e a preparação do acompanhamento seguinte com o } \\
\text { material disponibilizado. }\end{array}$ & $\begin{array}{l}\text { Junho a novembro } \\
\text { de } 2019\end{array}$ \\
\hline $\begin{array}{l}\text { Aprendizado } \\
\text { empreendedor }\end{array}$ & $\begin{array}{l}\text { Discussão de tópicos, como: resultado da pesquisa de mercado, } \\
\text { escolha do produto, escolha do nome da empresa, determinação } \\
\text { do capital social e entrega das ações. Na sequência, recebimento } \\
\text { e registro das ações (capital inicial), finanças - determinação } \\
\text { dos custos, organograma, preparação para a eleição da diretoria, } \\
\text { apresentação e do protótipo do produto. Por fim, divulgação, } \\
\text { vendas e acompanhamento. }\end{array}$ & $\begin{array}{l}\text { Junho a novembro } \\
\text { de } 2019\end{array}$ \\
\hline $\begin{array}{l}\text { Palestra com } \\
\text { empresário regional }\end{array}$ & $\begin{array}{l}\text { Palestra com um empresário da região, convidado a compartilhar } \\
\text { conhecimento acerca de sua pequena fábrica, visto que o produto } \\
\text { escolhido pelos alunos do projeto apresentava relação direta com } \\
\text { o processo produtivo da empresa do palestrante. }\end{array}$ & Outubro de 2019 \\
\hline Finalização do projeto & $\begin{array}{l}\text { Fechamento dos relatórios de acompanhamento, confraternização } \\
\text { e entrega de certificados. }\end{array}$ & $\begin{array}{l}\text { Novembro de } \\
2019\end{array}$ \\
\hline
\end{tabular}

Fonte: Quadro elaborado pelos pesquisadores (2020).

Essas atividades foram sempre acompanhadas pelo coordenador do projeto, pelos 3 professores colaboradores e pelos 8 (sendo 7 do sexo feminino, incluindo a bolsista, e 1 do sexo masculino) advisers (denominação adotada pela metodologia da JA para os alunos colaboradores da universidade), com a intenção de monitorar o desenvolvimento dos envolvidos, em especial os achievers (denominação adotada pela JA para alunos da escola de ensino fundamental e médio).

Aconteceram discussões a cada etapa finalizada, em que foi apontado e analisado o que teria ocorrido, bem como discutida uma prévia para o próximo encontro ou jornada, visando entender qual contribuição acontecera, tanto por parte dos achievers, quanto dos advisers.

Abaixo, segue foto de uma das jornadas produtivas: 


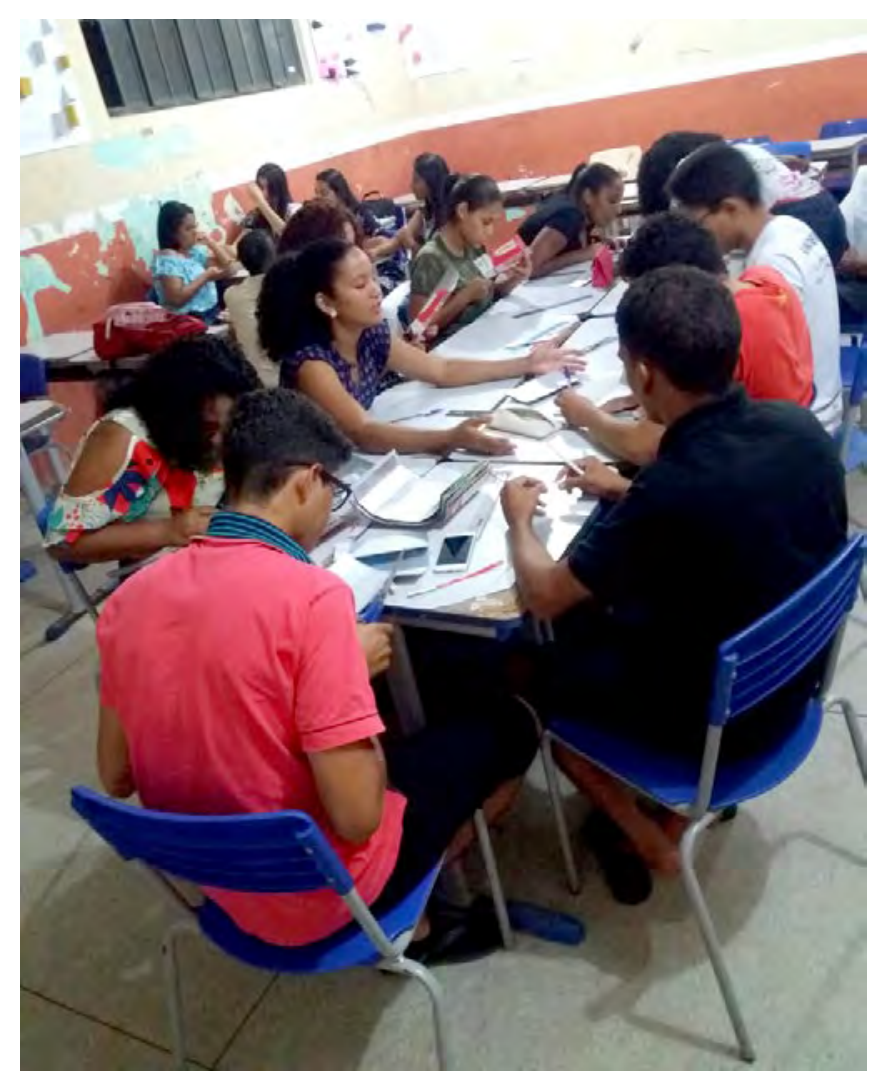

Fonte: Arquivos dos pesquisadores (2020).

\section{Resultados e discussão}

A participação no projeto pôde proporcionar vários aprendizados, dentre eles os decorrentes da técnica do brainstorming. Por meio da tempestade de ideias, chegou-se à decisão do produto que os achievers fariam e à posterior decisão do nome da empresa. Houve (e concretizou-se) o intuito de conscientizá-los sobre a importância de um nome que inspirasse confiança e credibilidade - o peso de uma decisão.

Outro aprendizado oferecido foi oportunizar conhecimento de como funcionam as quatro principais áreas de uma empresa: Marketing, Finanças, Recursos Humanos e Produção além de proporcionar troca de informações e conhecimentos de empresa como um todo. No âmbito teórico trabalhou-se o conceito de empresa, suas origens e tipos, bem como os valores sociais da livre iniciativa. Conjuntamente, empreendeuse a funcionalidade na prática, com a criação e venda de um produto.

Em relação ao desenvolvimento das aprendizagens em grupo e de impulso ao desenvolvimento cognitivo (aspectos socioemocionais e cognitivos), foram proporcionados interação e compartilhamento de conhecimentos entre os participantes, o que os tornou aptos ao desenvolvimento sistemático além de estimular um raciocínio sobre determinada atividade exercida por eles. Nesse processo, o aprendizado tornase efetivo e, por consequência, como citado por Alves et al. (2016), modifica comportamentos. Constatou-se, ainda, o que os referidos autores mencionam sobre o Ciclo de Aprendizagem Presencial (CAP): ele incentiva os participantes a se integrarem no processo de solução de um problema, desafio ou atividade.

$\mathrm{Na}$ produção ou elaboração das bolsas, propriamente, os alunos passaram por um estágio em que os líderes de cada departamento explicaram suas respectivas funcionalidades para os funcionários dos demais gerentes. Dessa forma, foi possível gerar compreensão de como funciona cada departamento e, por conseguinte, ampliar a percepção de chão de fábrica na empresa que criaram.

Produzindo ecobags, os alunos puderam ter uma experiência do que seria estar em uma empresa de verdade dirigida por eles, além de vivenciar percalços de quem é empreendedor no Brasil. Como em qualquer empresa, dificuldades podem ocorrer, e na empresa dos alunos não foi diferente. 0 projeto, que iniciou com 30 estudantes, finalizou com 12 . Houve, também, perdas e desperdícios na produção das bolsas. Por outro lado, isso fez com que os alunos refletissem acerca dos gastos e começassem a economizar, poupar e usar 
de forma consciente os materiais da produção. Da fabricação de 29 bolsas, apenas 23 foram vendidas, visto que os alunos afirmaram encontrar dificuldades na "hora" das vendas.

Segue foto ilustrativa das ecobags, em fase de acabamento:

Figura 2: Ecobags

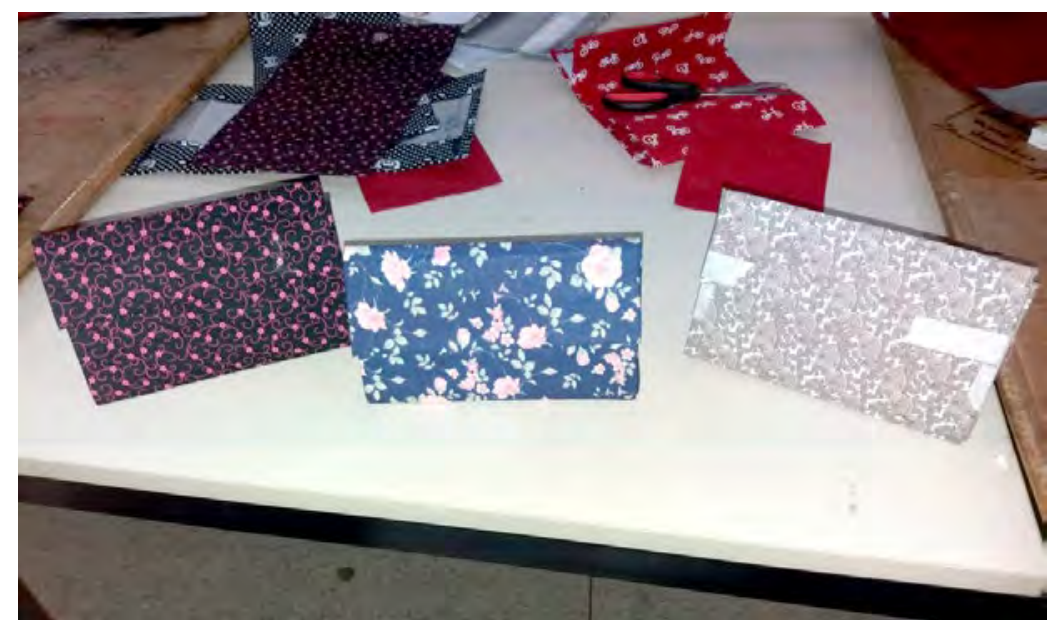

Fonte: Arquivos dos pesquisadores (2020).

Os conflitos de má gestão e controle que a diretora de produção enfrentou, para citar um exemplo, não passaram despercebidos, bem como a insistência da aluna responsável pela produção em desistir do projeto. Essas situações foram resolvidas com alternativas para gerir e formas de lidar com os alunos e suas responsabilidades. Como lembrado por Lopes (2010), a educação empreendedora é distinta do ensino tradicional por priorizar mais a atividade do próprio aluno em um modelo experiencial, prático e contextualizado ao mundo real.

Embora a empresa tenha apresentado um saldo de prejuízo, a experiência na participação do projeto contribuiu com a comunicação e aproximação de alunos de turmas diferentes, proporcionou trabalho em equipe e lidar com responsabilidades e conflitos de âmbito empresarial.

Abaixo, segue foto do coordenador e da adviser bolsista do projeto com as ecobags:

Figura 3: Ecobags prontas - bolsista e coordenador:

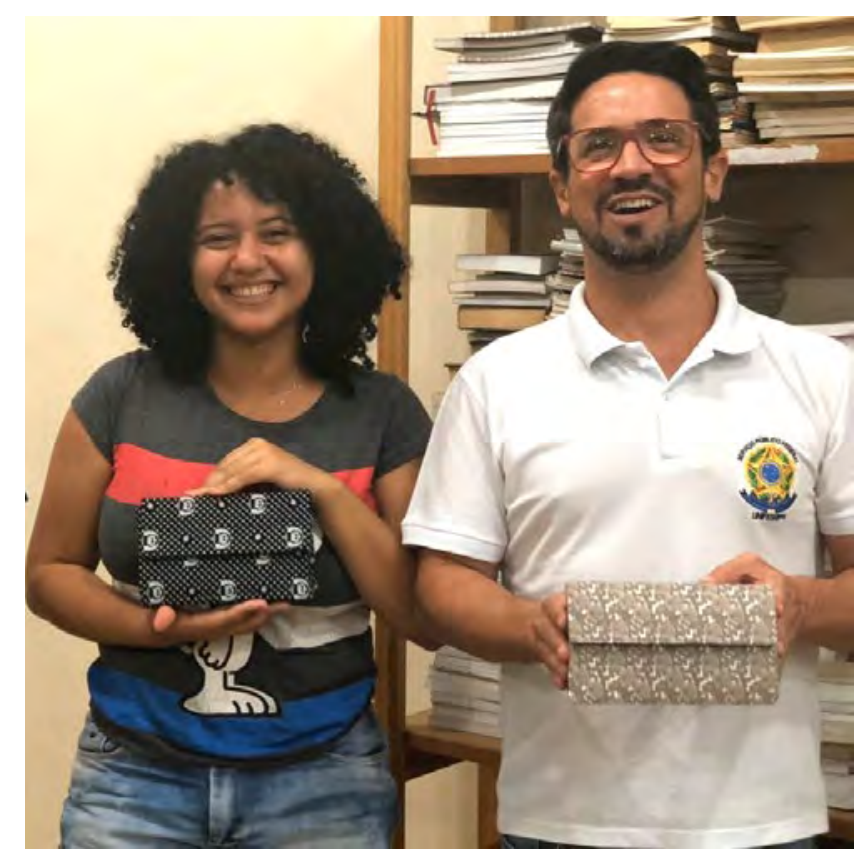

Fonte: Arquivo dos pesquisadores (2020) 
A seguir, são apresentadas falas de alunos da escola (elencamos os alunos com cargos de direção na miniempresa), quando solicitado a eles que descrevessem a experiência de forma rápida:

0 Aluno 1 mostrou interesse no decorrer do projeto e pontuou que conseguiu entender o grau de complexidade à medida que as jornadas iam acontecendo:

...quando eu cheguei lá era um grupo de professores que "tava" com o objetivo de ensinar os alunos a ver a realidade de uma empresa, e daí eu me interessei... $\mathrm{E}$ quando foi passando as jornadas, houve a candidatura para ser diretor e daí eu me candidatei e fui eleito a ser o diretor financeiro e a partir daí eu comecei a enxergar de uma maneira mais profunda como é trabalho de uma empresa. Foi algo que me acrescentou muito. (ALUNO 1).

O Aluno 2 apontou que foi surpreendido positivamente, visto que não esperava que teria que, de fato, produzir algo. Isso despertou mais interesse e estímulo ao aprendizado:

No primeiro dia eu imaginava que a tal empresa...eu seria algo mais fictício...que eu não esperava que a gente teria que botar a mão na massa....aí só que quando caiu a ficha falei: "a gente vai ter mesmo que produzir!"...aí foi quando eu comecei a encarar de fato toda situação. Aí a cada momento a gente tinha, descobria que não é fácil montar uma empresa... e assim tem que ter muito trabalho, tem que saber muitas coisas, tem que ter pesquisa de mercado.... Mas assim... aí no processo da montagem da bolsa, a gente enfrentou muitos desafios, porque muita gente não tinha domínio. Mas foi muito bom. E assim, correr atrás de gente pra saber porque que tá faltando...porque você tem justa causa...tem que cobrar, não pode...tem que haver aquela cobrança... . Então a produção não pode parar porque tem cliente, então se a gente parar, os clientes desistem da gente. Mas assim, eu não esperava ser do RH. Foi muito novo pra mim. Tudo basicamente, mas foi uma experiência muito boa (ALUNO 2).

A Aluna 3 também apontou para uma surpresa positiva, no sentido que esperava algo menos dinâmico, além de não esperar que uma empresa pudesse apresentar tão alto grau de complexidade:

Minha expectativa era aula entediante, videoaulas e sala de aulas...tudo muito chato. Tivemos um processo de começar uma empresa totalmente do começo, sem saber se realmente iria dar certo....tive a oportunidade de ser diretora de produção e no começo não foi muito fácil, mas com a ajuda dos orientadores, deu tudo certo. Gostei muito de participar, sei que aprendi muitas coisas que irão me ajudar bastante no futuro e na minha opinião todos os participantes tiveram uma experiência muito boa. Foi uma pressão um pouco forte...por causa que...no começo eu era a única que sabia da...dos processos de produção .... Daí eu "tava" sentindo como se tudo fosse culpa minha ... eu tinha dado a ideia e as pessoas não "tavam" aprendendo... porque para um funcionário ser admitido ele tem de ser qualificado no que ele vai trabalhar. (ALUNA 3).

\section{Considerações finais}

Foi observado que os alunos da escola de ensino médio apresentaram bom desenvolvimento no âmbito empreendedor, melhoria no trabalho em equipe e em assumir riscos calculados. Por meio do brainstorming e das discussões que se seguiram em formato de reuniões, despertando a atenção para a necessidade de planejamento, eles se tornaram inovadores ao eleger um produto para vendas.

0 projeto auxiliou no desempenho dos alunos ao mostrar a funcionalidade de uma empresa real e suas departamentalizações em Marketing, Produção, Recursos Humanos e Finanças. A necessidade de rearranjar planos, as consequências desses rearranjos e as evidências de que, se não tivesse havido um planejamento, os resultados poderiam ser piores, fizeram com que os aprendizes entendessem a complexidade do processo de uma miniempresa.

Ficou claro nas falas dos alunos que eles não mais entendem uma empresa como enxergavam antes do projeto; eles pensavam empresa como algo bem mais simples, com menos necessidade de controle, de acompanhamento.

0 relacionamento entre os achievers e toda a equipe pôde ser observado no período em que aconteceram as jornadas (encontros), em uma evolução, no sentido de que foi se construindo uma 
comunicação necessária para fazer os processos acontecerem. Espera-se que esse aprendizado seja útil em outros momentos nas vidas dos envolvidos (pessoal e profissional).

Pode-se dizer que um desafio enfrentado pela equipe do projeto foi conseguir o comprometimento dos alunos do colégio desde o início ao término das jornadas. No entanto, entende-se que o saldo do nível de comprometimento foi positivo, levando em consideração a satisfação demonstrada no dia do encerramento e entrega dos certificados.

A segunda edição do projeto, aprovado pela Pró-Reitoria de Extensão da universidade, está em fase de execução. Os alunos participantes dessa segunda edição, agora do segundo ano do ensino médio, já foram contatados e provavelmente as novas reuniões serão iniciadas em breve.

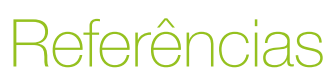

ALVES, William Moreira; SILVA, Guilherme Luis Rosa; PROTIL Roberto Max; ALBINO Pablo Murta Baião. Avaliação do Ciclo de Aprendizagem Vivencial em uma Cooperativa Agropecuária. Revista ELO-Diálogos em Extensão, v. 5, n. 1, 2016.

BAGGIO, Adelar Francisco; BAGGIO, Daniel Knebel. Empreendedorismo: conceitos e definições. Revista de empreendedorismo, inovação e tecnologia, v. 1, n. 1, p. 25-38, 2015.

BIZZOTTO, Carlos Eduardo Negrão; DALFOVO, Oscar. Ensino de empreendedorismo: uma abordagem vivencial. In: Anais do II EGEPE. Londrina, Paraná, 2011. p. 142-153.

BRASIL, Lei 13.415 de 16 de fevereiro de 2017. Altera as Leis $n$ ㅇ 9.394, de 20 de dezembro de 1996, que estabelece as diretrizes e bases da educação nacional, e 11.494, de 20 de junho 2007, que regulamenta o Fundo de Manutenção e Desenvolvimento da Educação Básica e de Valorização dos Profissionais da Educação, a Consolidação das Leis do Trabalho - CLT, aprovada pelo Decreto-Lei no 5.452, de 1o de maio de 1943, e o Decreto-Lei no 236, de 28 de fevereiro de 1967; revoga a Lei no 11.161, de 5 de agosto de 2005; e institui a Política de Fomento à Implementação de Escolas de Ensino Médio em Tempo Integral. Disponível em : http:/l www.planalto.gov.br/ccivil 03/Ato2015-2018/2017/Lei/L13415.htm Acesso em 07 de março de 2021

DOLABELA, Fernando. $\mathbf{0}$ segredo de Luísa. Uma ideia, uma paixão e um plano de negócios: como nasce o empreendedor e se cria uma empresa. São Paulo: Cultura, 2006.

DOLABELA, Fernando; FILION, Louis Jacques. Fazendo revolução no Brasil: a introdução da pedagogia empreendedora nos estágios iniciais da educação. Revista de Empreendedorismo e Gestão de Pequenas Empresas, v.3, n.2, p. 134-181, 2013.

DORNELAS, José. A. Empreendedorismo: transformando idéias em Negócios. 3. ed. Rio de Janeiro: Elsevier, 2008.

DRUCKER, Peter Ferdinand.Inovação e espírito empreendedor: práticas e princípios. São Paulo, Cengage Learning, p. 400, 2017.

DRUZIAN, Gustavo Lau; JARDIM, Matheus Silveira; SILVA, Ana Carolina C, Josende; GUSE, Jaqueline Carla; KESSLER Márcia Samuel; GHISLENI, Taís Steffenello. Educação empreendedora: Estudo de caso com alunos em uma escola estadual da região central do Rio Grande do Sul. Disciplinarum Scientia. Série: Sociais Aplicadas, Santa Maria, v. 12, n. 1, p. 31-41, 2017.

GASKELL, George. Entrevistas individuais e grupais. In: MARTIN, Bauer; GASKELL, George. (Orgs.), Pesquisa qualitativa com texto, imagem e som: um manual prático. Petrópolis: Vozes, 2014, pp. 64-89.

GIL, Antônio Carlos. Métodos e técnicas de pesquisa social. São Paulo: Atlas, 1994.

HENRY, Colette.; HILL, Frances.; LEITCH, Claire. Entrepreneurship education and training: can entrepreneurship be taught? part 1. Education + Training, v. 47, n. 2, p. 98-111, 2005.

JUNIOR ACHIEMENT BRASIL. MINIEMPRESA. Manual do Achiever. Associação Junior Achievement do Brasil, Porto Alegre,2014. 

$03 / 02 / 2021$.

Sobre a JA. JA BRASIL,2021. Disponível em < https://www.jabrasil.org.br/sobre-nos>. Acesso em:

LOPES, Rose Mary Alameida. Referenciais para a educação empreendedora. In: LOPES, R. M. A. (Org.). Educação empreendedora: conceitos, modelos e práticas. Rio de Janeiro: Elsevier: São Paulo: SEBRAE, 2010.

LORENTZ, Márcia Helena Nascimento. 0 comportamento empreendedor de diretores da UFSM e sua percepção quanto à universidade empreendedora. 2015. 155 p. Dissertação (Mestrado) - Universidade Federal de Santa Maria, Programa de Pós-graduação em Administração, 2015.

MALACARNE, Robson; BRUNSTEIN, Janete; BRITO, Margarete Dias Formação de Técnicos Agropecuários Empreendedores: 0 caso do IFES e sua participação na OBAP. REGEPE-Revista de Empreendedorismo e Gestão de Pequenas Empresas, v. 3, n. 2, p. 20-41, 2014.

MENDES, Maria Teresa Teixeira 2011. 288p. Educação Empreendedora: uma visão holística do empreendedorismo na educação. Dissertação (Mestrado em Ciências da Educação) - Universidade Católica Portuguesa, Faculdade de Educação e Psicologia. Lisboa, 2011.

NECK, Heide M.; GREENE, Patricia. G. Entrepreneurship education: known worlds and new frontiers. Journal of Small Business Management, v. 49, n. 1, p. 55-70, 2011.

NEUMAN, William Lawrence. Social research methods: qualitative and quantitative approaches. Boston : Allyn \& Bacon,1997.

SARASVATHY, Saras. D.; VENKATARAMAN, Sankaran. Entrepreneurship as method: open questions for an entrepreneurial future. Entrepreneurship theory and practice, v. 35, n. 1, p. 113-135, 2011.

SCHAEFER, Ricardo; MINELLO, Italo Fernando. Educação empreendedora: premissas, objetivos e metodologias. Pensamento contemporâneo em Administração. Rio de Janeiro. v. 10, n. 3, p. 60-81, jul./set. 2016.

SILVA, Júlio Fernando da.; PENA, Roberto Patrus Mundim. O “Bê-Á-Bá" do Ensino em Empreendedorismo: uma revisão da literatura sobre os métodos e práticas da educação empreendedora. Revista de

Empreendedorismo e Gestão de Pequenas Empresas, v. 6, n. 2, p. 372-401, 2017.

SILVA, Fabiane da Costa.; MANCEBO, Rafael Cuba.; MARIANO, Sandra Regina Holanda. Educação empreendedora como método: o caso do Minor e inovação da UFF. REGEPE-Revista de Empreendedorismo e Gestão de Pequenas Empresas, v. 6, n. 1, p. 196-216, 2017.

TSCHÁ, Elizabeth Regina.; CRUZ NETO, Genésio Gomes. Empreendendo colaborativamente ideias, sonhos, vidas e carreiras: 0 caso das células empreendedoras. In: GIMENEZ, Fernando Antônio Prado. Emerson Carneiro Camargo; Alexandre Donizete Lopes de Moraes; Franciele Klosowski. (Org.) Educação para o empreendedorismo. Curitiba: Agência de Inovação da UFPR, 2014.

VIEIRA, S. F. A.; MELATTI, G. A.; OGUIDO, W. S.; PELISSON, C.; NEGREIROS, L. F. Ensino de empreendedorismo em Cursos de Administração: um levantamento da realidade brasileira. Revista de Administração FACES , v. 12, n. 2, p. 93-114, 2013.

YUSOFF, Mohd Nor Hakimin Bin.; ZAINOL, Fakhrul Anwar.; IBRAHIM, Mohamed Dahlan Bin Entrepreneurship Education in Malaysia's Public Institutions of Higher Learning: a review of the current practices. International Education Studies, v. 8, n.1, p. 17-28. 2015. 